\title{
Comparison of Species Abundance Distributions in the Forests of Iran North
}

\author{
Vahab Sohrabi \\ M.Sc. student Dept. of Forestry, Gorgan University of Agriculture Sciences, and Natural Resources \\ Babol, Mazandaran, Iran \\ Tel: 91-1857-2554 E-mail: sohrabivahab@yahoo.com \\ Ramin Rahmani, Mohammad Hadi Moayeri \& Shahrokh Jjabbari \\ Associate Prof. Dept. of Forestry, Gorgan University of Agricultural Science and Natural Resources \\ Babol, Mazandaran, Iran \\ E-mail: rahmani@gau.ac.ir
}

Received: February 28, 2011 Accepted: June 9, 2011 doi:10.5539/ijb.v3n3p156

\begin{abstract}
To compare the abundance distribution models of species in the forests of iran north (Golestan province) 6 sites of forests were selected that in each of site, 30 modified whittaker plots in range of 850-950 altitude from the sea level in north aspect were located. In this $20 \times 50 \mathrm{~m}^{2}$ frame, the species name and frequency of trees and shrubs recorded. Then said information give to BIO-DAP software. This software order species based on its frequencies and fit the best abundance distributions on data with showing digits. The results showed that, the gorgan beech site has most fitness with logarithmic series models and then log normal. The oak sites so, has most fitness first with lognormal model and then logarithmic series.
\end{abstract}

Keywords: Biodiversity, Species abundance distributions, Golestan forests (Iran north)

\section{Introduction}

The species richness simply is a number of species in a society. Nevertheless, it is unlikely; each species has a same number of members. In no experimental community, all the species have the same abundance. Some species much abundance, some average abundance and some just show a few base (Maguran, 1996). The investigation of abundance distribution of species, is one way if study in societies which estimate a mathematic model to show the number of species and their abundance distribution of species is used for gathering of all information of one community and is the most complete method of distribution data (Cielo et al, 2002., Oliveira, 2005). Despite of it's importance, there is less try to test the goodness of it's fitness in nature versus observed abundance distribution (Oliveira, 2005, Ejtehadi \& Akkafi, 2008). The abundance distribution of species in a community is can make the biological reasoning closer together (May, 1975.,, Whittaker, 1975., Sugihara, 1980). Raunchier (Raunkiaer, 1918), was the first person who suggest that may be there is relate between the species and their comparative abundance. From that time until now, different models to describe the richness and abundance sample like geometric series (Molles et al,1999), log series (Fisher et al,1943), normal log (Preston,1962), broken-stick (MacArthur,1957), multi species logistic (Dewdney,2003) are suggested (Figure1). One way of showing the data related species abundance is rank-abundance plots. In such plots species abundance in logarithmic measure placed of axis (horizontal) against species abundance bonds (from much abundance to few) on the axis (vertical). These plots show the species form for each of four above models. It means, for the first and second model (create) a right line with speedy slope and for third model a sigmoid curve and for the forth model a complete steady curve with moderate slope (Fisher et al,1943., Molles et al,1999., Tothmeresz,1993., Tothmeresz,1995). with considering to rank- abundance plots are used for showing the condition of range region, should investigated the way of real distribution of species abundance of each regional also variance model and certainly of match ness of form with real data, that this action done with the match ness test. As show before, a few studies carry out for fitness of these models with nature samples, Iran especially in Golestan forest. Ahmadi's (Ahmadi,2000) investigation results shows about the influence of 3 methods of 
harvesting: single selection system, group single selection system and strip cutting on biodiversity of academic and research forest (shast kalateh) that among the different systems, the single selection system, have the most variance with broken- stick model which show suitable distribution among species. Considered to that the Golestan province forests are the most consider part of the north forests (Hyrcanian forests), and after that is kind of forests finished, and the beech and oak forests specifically and the Golestan province forests generally are unique, So, to protect them, we should be aware of environmental factors which influence on variation. Considering that in nature gradient, the change if variation exists, we investigate the condition of these changes with considering to the species abundance models.

\section{Material and method}

\subsection{The regions of study}

To investigation this study, 6 sites ((beech stand of gorgan, carpino-parroteum of aliabad, carpinus betulus stand of azadshahr, carpino-quercetum of takht, oak stand of farsian and oak stand of loveh) in golestan province (north of Iran) are selected. These regions selected because of the altitude from the sea level and equal aspect and distance. The regions mostly are virgin and in some are least interfering of human.

2.1.1 The gorgan research and academic shast kalateh forest is located in the northern slope of alborz mountain range and this mountain range is stretched to the south of caspian sea from east and west. This forest is located latitude 36 degree and 47 minutes to 36 degree and 45 minutes of north and in longitude of 51 degree and 20 minutes to 54 degree and 21 minutes in east. Its expanse is 3116 hectares. Its annual rainfall measure is 649 millimeters.

2.1.2 The tavir forestry plane is expanded from 4 kilometer is south of fazel abad toward in vertical at distance with nodeh malek crossroads to fazel abad. (This series of forests placed between the longitude of 54-45-12 to 54-40-9 and latitude of 26-5-20 to 36-47-29). The annual rainfall measure is 474 millimeter.

2.1.3 Kohmian forestry plan is located in 98 watershed domain which is limited in north is village of kohmian, fazel abad, khanduz sadat and marzbone, in south and west to naeem s forestry plan and in east to vatan forestry plan. Its east longitude is 55-14-49 to 55-10-30 and its north width is 37-65-15 to 37-00-00 degrees.

2.1.4 The first series of the takht forestry plan is located in the northeast of 91-watershade domain. The takht series of forests are limited from north to minudasht city, from south to yale sorkh, from east to rhg cheshmeh series and from west to narmehab river and the azadshahr, forestry is located. The region has north altitude of 37-07 to 37-13-30 and east longitude 55-27-20 to 55-22-35. The rainfall measurement series has $475 \mathrm{~mm}$ that parcel of 106 with expanse of $76 / 5$ hectares with 900 height of sea level by north aspect is choose.

2.1.5 Sijan kiaram forestry plan expanded in 900-1800 height of sea level which in south east of galikesh city in 93 water shade territory and galikesh forestry territory from the nature resource administration of gorgan and gonbad. The rainfall measurement is these regions are $65 \mathrm{~mm}$, which is variable between 486 to $856 \mathrm{~mm}$.

2.1.6 The third series of loveh (Cheshmeh-Shapour) forestry plan is located in the east part of alborz mountain range in golestan province and with part of 94-watershade galikesh. It has longitude of 55-41-00 to 55-46-00 and latitude of 37-19-00 to 37-20-00. Its four boundaries are limited from north to terjali villages' lands, from south to the first series of loveh, from east to protected forests of national park of golestan and from west to mohammad ail valley and the fourth series forests.

\subsection{Research method}

This research is base on sampling by systematic random system and the center of plots in forest is determined. To study and investigation, the number of modified whittaker plots in range of 850-950 altitude from the sea level in 6 site (in each site 30 plots) with least interfering of human in north aspect and with equal distance from each other and located. In this $20 \times 50$ meter frame, the names and frequency of trees and shrubs species recorded. To investigate the species diversity, there used from four models of logarithmic, log series, log normal and broken stick. After classification of data in excel software, the biodap software use for conformity of the models. This software order species based on its frequencies and fit the best abundance distributions on data with showing digits.

\section{Results}

The site of gorgan (First region) showed most fitness with logarithmic series and then log normal. farsian and loveh in minudasht region, aliabad and kohmian region showed most fitness with log normal model and then logarithmic series. Takht site showed the most fitness with log normal and there was no fitness with other models. Table(1) shows the abundance distribution models of species in sites, which are under investigation. As 
we seen in Table 1, The numbers are sign of models match. On the other hand, Number (1) show most fitness with logarithmic series. Thus, Sites of alia bad, azadshahr, takht, farsian and loveh have most fitness with log normal and gorgan site has most fitness with logarithmic series.

\section{Discussion}

At first logarithmic series model use to describes the relation between the number of species and the number of specie member as mathematical way in many of sample units, the number of species with on individual is plentiful and species with two individual has less abundance and in this matter, a few of the species contains a lot of individuals. Logarithmic series seen in society, which has a few number of species, and dominant environmental element, controls the abundance of species (Ejtehadi et al, 2009., May, 1975). This condition shows the intense invasion of ecological niche. According to sogihara's idea (Ejtehadi et al,2009., Sugihara,1980), species abundance pattern of most studied societies by ecologists, is log normal form. That is each species in accordance with its relative abundance; occupy a part of ecological niche. Upon this model, species with average abundance are many and species with too much or too less abundance are a few. Log normal distribution, has a statistics feature of large number of data which obtained is result of central limit issue. As central limit issue states, when there are a large number of data to explain a unstable casual changes among the data result to that unstable cause that the distribution of that data follow the normal distribution (Ejtehadi et al, 2009). As consider in figure(2), beech site of gorgan, shows the most fitness with logarithmic series and then log normal. If logarithmic model presented on a society, it shows that the number of species with low rate is very high and the number of species with high rate is very low. This kind of models indicates the societies with low biodiversity. Beech type is a pure type and the beech species form most number of its member that has agreement with the definition of model, and a dominant environmental element controls the abundance of species that this fact may cause by moisture of region. In other hand, beech is a tolerant species and when is near to its succession, reduce the presence of other species around itself. Site of Carpino-Paroteum in aliabad region shows the most fitness with lognormal model and then logarithmic series. Majority of normal log model on one society specify that the number of species with average rate is very high. This model shows the society with high diversity and richness of species and stability. Pay attention to that in this region sanitary cut once way done, seem it affect on forest, and it reduce the majority of carpinus species. Carpinus betulus type in kohmian region in azadshahr too shows the most fitness with lognormal model and then logarithmic series, which shows species with average abundance and in fact, is a heterogenic environment. Pay attention that in this region sanitation cutting done too seems in this type too, carpinus sp is losing its majority, because cuts lead to appearance of light demanding species and as result the heterogeneity and diversity of the region. In the carpino-paroteum site in takht region the most fitness, belong to log normal. Probably because of the accompanying of oak species in this type species diversity increase which each appropriate with its need devote a part of ecological resource. Oak site of loveh was under harvesting with shelter wood system in many years that this event. The domination of oak species and make logarithmic series close to log normal to consider that the oak species are less and carpinus betulus species is replaced it, its necessary to stop its expansion. This is possible by using of silviculture of close nature.

\section{Acknowledgements}

Hereby I give my gratitude to my parents that owed my life to them and also to my dear wife.

\section{References}

Ahmadi, sh. (2000). Efect of harvesting on biodiversity in research and academic shastkolateh forest of gorgan, M.Sc thesis, Gorgan University of Agriculture Sciences and Natural Resources, forestry faculty.

Ejtehadi, H., Sepehry, A., \& Akkafi.,H.R. (2009). Method of measuring biodiversity.ferdoesi university of mashhad publication, No.530.

Ejtehadi, H., \& Akkafi.,H.R. (2008). Investigation of species diversity by abundance distribution models, JSIAU, 66:63-72.

Akkafi, H. R., \& Ejtehadi, H. (2007). Investigation species diversity of two regional by frequency distribution models. journal of science azad university, 66:63-72.

Cielo filho, R., Martins, F.R. \& Gneri, M.A. (2002). Fitting abundance models in tropical arboreal communities of SE Brazil. Community Ecology, 3:169-180.

Dewdney, A.K. (2003). The stochastic community and the logistic J-distribution. Acta Oecologica, 24:221-229. 
Fisher, R.A., Cobert, A.S. \& Williams, C.B. (1943). The relation between the number of species and the number of individuals in a random sample of an animal population. Journal of Animal Ecology, 12:42-58.

Gray, J.S. (1987). Species-abundance pattern. In Organization of communities, past and present (J.H.R. Gee \& P.S. Giller,eds.). Blackwell Science, Oxford, p. 53-67.

MacArthur, R.H. (1957). On the relative abundance of birds species. Proceeding of the National Academy of Science, 43:293-295.

Maguran, A.E. (1996). Ecological diversity and its measurement. Princeton University, Princeton.

May, R.M. (1975). Patterns of species abundance and diversity. In Ecology and evolution of communities (M.L. Cody \&J.M Diamond, eds.). Harvard University, Cambridge, p.81-120.

Motomura, I. (1932). A statistical treatment of associations. Japanese Journal of Zoology, 44:379-383.PRESTON, F.W. 1948. The commonness and the rarity ofspecies. Ecology 29:254-283.

Molles, M. C. (1999). Ecology:concepts and application, WCB Mc Graw-Hill.

Oliveira.F.F., \& Batalha.M.A. (2005). Lognormal abundance distribution of woody species in a cerrado fragment(São Carlos, southeastern Brazil). Revista Brasil. Bot., V.28, n.1, p.39-45, jan.-mar.

Preston, F.W. (1962). The canonical distribution of commonness and rarity. Ecology, 43:185-215.

Raunkiaer, C. (1918). Recherches statistiques sur les formations végétales. Biologics Meddeleser Kongelige Danske Videnskabernes Selskab 1:1-80.

Sugihara, G. (1980). Minimal community structure: an explanation of species abundance patterns. The American Naturalist, 116:770-787.

Tothmeresz., B. (1993). Journal of Vegetation Science, 6, 683.

Tothmeresz, B. (1995). Journal of Vegetation Science, 6, 283.

Whittaker, R.H. (1972). Evolution and measurement of species diversity. Taxon 21:213-251.

Table 1. The fitness of sites investigated using species abundance distributions

\begin{tabular}{|l|c|c|}
\hline \multicolumn{3}{|c|}{ species abundance distributions } \\
\hline Site & Logarithmic & Log normal \\
\hline Gorgan & 1 & 2 \\
\hline Ali Abad & 2 & 1 \\
\hline Azadshahr & 2 & 1 \\
\hline Takht & - & 1 \\
\hline Farsisn & 2 & 1 \\
\hline Loveh & 2 & 1 \\
\hline
\end{tabular}

The numbers are sign of models match 


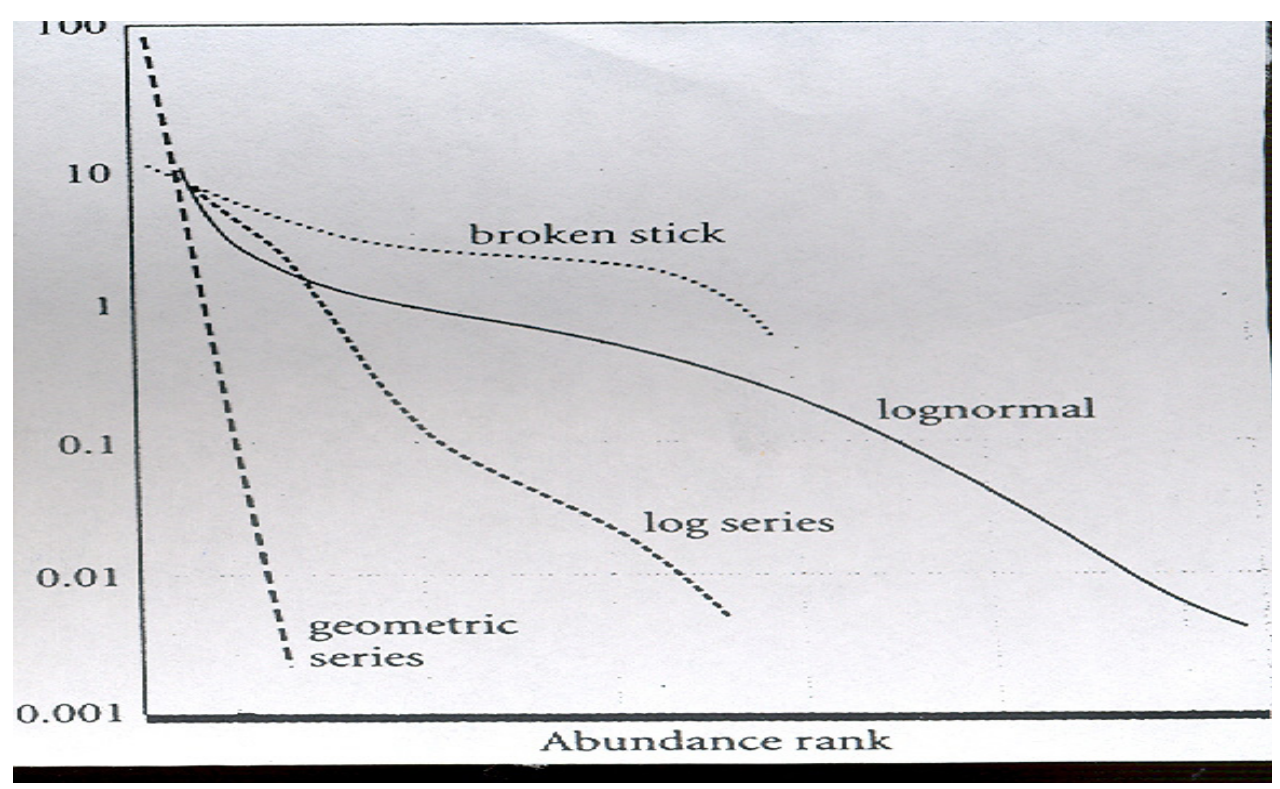

Figure 1. Showing of species abundance distributions

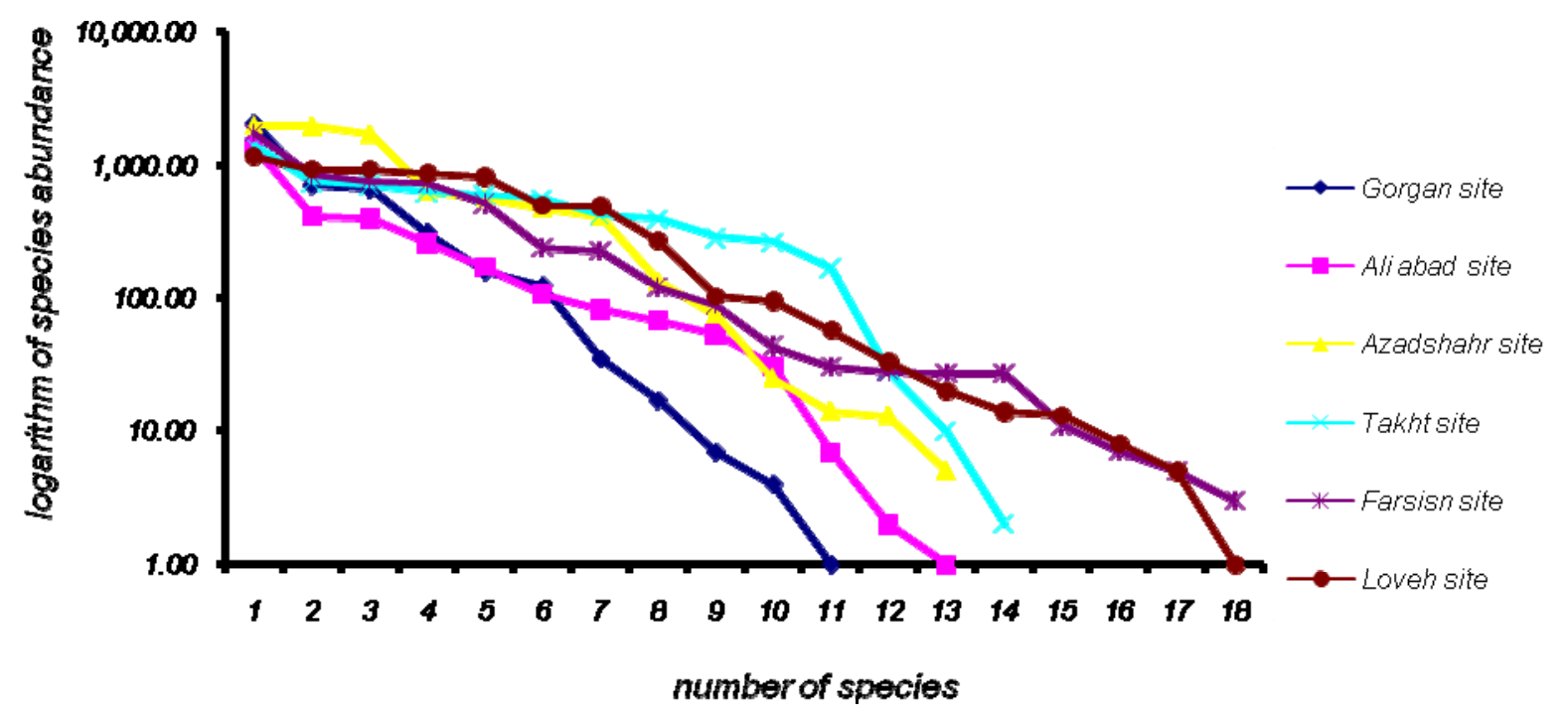

Figure 2. Species abundance distributions 